\title{
Rabbit Production in Semi Arid Zone of Sokoto State
}

\author{
Salihu Abdullahi Abubakar ${ }^{1}$ and Abdulrahman Bello ${ }^{2 *}$ \\ ${ }^{1}$ Department of Agricultural Technology, Umaru Ali Shinkafi Polytechnic, Nigeria \\ ${ }^{2}$ Department of Veterinary Anatomy, Usmanu Danfodiyo University, Nigeria \\ *Corresponding author: Abdulrahman Bello, Department of Veterinary Anatomy, Usmanu Danfodiyo University, Sokoto, Nigeria. \\ To Cite This Article: Abdulrahman Bello, Rabbit Production in Semi Arid Zone of Sokoto State. 2020 - 7(3). AJBSR.MS.ID.001147. \\ DOI: 10.34297/AJBSR.2020.07.001147.
}

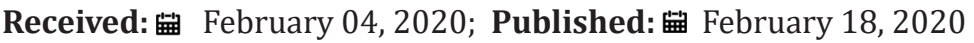

\begin{abstract}
The paper was compelled to educate student and farmers in the area of Rabbit Production. The paper tries to summarize so many literatures in order to easy the act of learning rabbit production in relation to the regional weather of Sokoto state. There have been series of studies and papers on rabbit production but not even a single study has been carried out on the management of rabbit production by peasant farmer in relation to the weather condition in Sokoto south local government of Sokoto state.
\end{abstract}

Keywords: Rabbits production; Nigeria; Stock size; Farmers

\section{Introduction}

Rabbits production in Nigeria plays a significant role in the development and provision of food and materials for marketing purposes; however there are some problems which may be affecting the production of rabbit in Nigeria; these problem could be poor management procedure, poor funding and lack of treatment measure for health problem promotion rabbit production area of agriculture and un ability to select good breed stock for rearing by the farmer, Secondly there have been series of studies on rabbit production but not even a single study has been carried out on the management of rabbit production by peasant farmer on Sokoto south local government of Sokoto state.

\section{Socio-Economics Characteristics of Rabbits Farmers}

The socio-economic characteristics of the rabbit's farmers consist of the distribution of farmers in age, gender, marital status, stock size and other characteristics. The distribution of rabbits farmers by occupation which was prove to be $33 \%$ of all farmers are government employees (civil servants, teachers, etc)while 39\% and $28 \%$ represent private sector(artisans, business man, farmers, etc) and others (student, retirees, etc) respectively. This trend shows that those engaged in rabbit farming cut across all professions and walks of life in the society [1].Also the distribution of rabbit farmers by person(s) in charge of the units by purpose for keeping rabbits is a significant proportion of the farmer(60\%) indicated that the primary reasons for keeping rabbits for consumption with occasional sales of excess stocks. this implies that rabbit keeping serves the primary goal of providing supplemental protein for the household. others (18\%)multiple reasons for establishing enterprise [1].furthermore the distribution of rabbit farms by type of material use for cage construction and the distribution of rabbit farms by type of cage design are also analyze to be mostly place outside the house(67\%)while the remaining units place their cages inside their houses because of thieves or to maximize the effect of heat stress [1].

\section{Management of Rabit BY Peasant Farmer}

The management of rabbit is done on a small- scale by a peasant farmer is raised for many different uses, and they can play an important role in a small sustainable family operation. While the most common use in agricultural industries is for meat, rabbit also is raised for pelts, manure, show, and laboratory use. Rabbit meat is highly protein and low in fat, calories, and cholesterol when compared to most of the meat eaten in the United States [2].

Rabbits are prolific and will breed year-round in well managed Rabbitries. Does have been known to kindle (give birth) up to 23 
kits at one time. The average litter size is eight. Rabbits usually have four to five litters per year. With proper management, rabbits can be kindled more intensively. Rabbit are ready for market at four to five pounds. It usually takes eight weeks to reach this weight with proper care and feeding. Rabbits have an efficient feed conversion ratio - the amount of feed consumed per pound of body weight gain. A doe can produce up to 10 times its own weight, or more in offspring per year. Rabbit meat is one of the most nutritious meats available. It is the highest in protein, lowest in fat and cholesterol, has the least number of calories per pound and has only eight percent bone.

Management of rabbits for meat production is quite different from the maintenance of a pet or house rabbit. One should give careful consideration to essential elements of a rabbit production system. As with any livestock enterprise key elements of labor, facilities, and lifestyle should be considered. Conducting the necessary background investigation initially will preclude mistakes later on. Other key concerns for rabbit production include sanitation and health, nutrition, reproduction, and breeding [3].

\section{Housing}

Housing requirements for rabbits depend on climate. Minimal housing consisting of an " $\mathrm{A}$ " frame without sides can be used in moderate climates, while a climate-controlled rabbitry may be necessary in hot or cold climates. Rabbitries should be located on nearly level ground and use well-drained soil or tile-drained pits for manure. Shade should be provided over as much of the rabbitry as possible. Good ventilation at all times is imperative. Narrow buildings of modular construction offer the advantages of easy ventilation and expansion as needed.

\section{Sanitation}

Sanitation is important in any livestock enterprise but is especially so in rabbit production. Poor sanitation leads to disease and deaths; therefore, cleaning and sanitizing must be constant. Nest boxes must be disinfected between uses. Cages, feeders, and watering equipment should be sanitized periodically. An effective and inexpensive sanitizing solution is sodium hypochlorite (household chlorine bleach) added to water (1oz $/ 1 \mathrm{qt}$ ). This solution can be corrosive to metal. An active rabbitry constantly experiences a loose hair problem. Does pull hair from their bodies to make nests, and some of this hair become airborne disease. It sticks to almost any surface, including cages, ceiling, and lights, and must be removed periodically. Loose hair may become a source for bacterial or viral growth and contamination. The most effective ways to remove hair from cages are by washing or by use of a propane torch or flame. Washing, brushing, sweeping, and vacuuming also are effective in other parts of the rabbitry. Frequent manure removal is essential. Excess manure leads to unacceptable levels of ammonia in the air, which predisposes rabbits to respiratory disease. The manure can be composted in an efficient pit system.

\section{Nutrition}

Proper feeding is an important management practice. It is easy to overfeed or underfeed does and growing, adolescent rabbits (fryers). The amount to feed depends on the age of the fryers, or on the stage of pregnancy or lactation of the does. A general rule in feeding fryers is to feed all that can be consumed in $20 \mathrm{hr}$, with the feed hopper empty $4 \mathrm{hr} /$ day. Does are usually fed ad lib once they kindle. The general practice is to bring the doe from restricted to full feed slowly during the first week of lactation. Does that are bred to kindle five-time s during the year generally have their feed restricted between litters; those bred intensively should be on full feed continuously once they begin the first lactation. Feeding rabbits has been greatly aided by nutritionally complete commercial pelleted diet, restricted to $1 / 4$ cup /5lb body weight/ day to prevent obesity. In the early morning or at night when they are unobserved, rabbits ingest part of their feces by contorting themselves so that the mouth touches the anus. They ingest only the soft matter that has been processed in the caecum. Coprophagy, or pseudorumination, is normal in rabbits and not a sign of nutritional deficiency. It serves an important nutritional function by supplying the rabbit with intestinally synthesized B vitamins and protein.

\section{Breeding}

Generally, small breeds mature earlier than larger ones. Polish can usually be bred at four months; medium weight rabbits at six to seven months; and giants at 9 to 12 months. Many commercial breeders begin breeding successfully at 5 months. The normal estrus cycle is 16 to 18 days, with two infertile days at the beginning and the end when the doe lacks interest in the buck. Rabbits are induced ovulators and ovulation occurs only after mating. The doe should always be taken to the male's hutch for breeding and not vice versa. If she does not mate within a few minutes, she should be removed and returned later. Does will show a false pregnancy following unsuccessful matings. This false pregnancy lasts 17 days, and the doe will not breed during this period. For this reason, most commercial breeders will generally rebreed the doe on the 18th day. Bucks should be used no more than 2 or 3 times per week, although they can be successfully maintained for every 20 does. The most important factor is to keep animals in top body condition. Overweight animals produce unsuccessful mating and poor litter quality.

\section{Kindling}

The normal gestation period is 31 days, and the doe will usually eat less, two or three days before kindling. The nest box should be placed in the hutch on the 28th to 29th day of kindling to avoid contamination. Most litters will be kindled at night, and the doe should not be disturbed while kindling. If the doe is not given seclusion, she will destroy the litter. After the litter is kindled, the doe pulls more fur from her body to make a nest. This plucking of fur is in no way harmful, except the doe's immediate appearance. 
Many breeders will keep several nest boxes with clean fur for first litter does and other does that do not pull enough to make a good nest. Since the average doe is equipped to nurse approximately eight young rabbits (kits) it is a common practice to breed several

\section{General Health Concerns}

Table 1.

Table 1: There are several general health concerns in rabbit husbandry.

\begin{tabular}{|c|c|c|}
\hline Table 1: There are several general health concerns in rabbit husbandry. & Treatment \\
\hline Disease/Condition & Symptoms & Do not feed intestine to Dogs or Cats \\
\hline Tapeworm infestation & Egg/larva in feces & Reduce intake of Greens \\
\hline Slobbers & Excessive Salivation & Treat with antibiotics \\
\hline Sore Hocks & Sores on Hocks & Increase Vitamin A or treat with ophthalmic antibiotic \\
\hline Sore Eyes & Watery, milky discharge around the eyes & Remove scabs and apply antibiotic ointment \\
\hline Vent Disease & Vent swollen, irritated, and scabby & Good Sanitation/Sulfa drugs in water \\
\hline Coccidiosis & Off feed, rough coat, low wt gain & \\
\hline
\end{tabular}

\section{Good Rabbits Breeds for Production}

The selection of rabbits breed is based on different criteria use by different farmers such as production performance, breed type, health status, growth rate and mothering ability etc, and this breed include newzeeland white, dutch, angora and Kenya white etc. (Jane et al. 2018) Domestication of the European rabbit probably occurred in monasteries during the Middle Ages. By the middle of the 17th century, rabbits were commonly raised in England and continental Europe. Oryctolagu cuniculus one of the more successful mammals of the world, is both prolific and adaptable. Most of the fancy breeds were developed within the last 100 years, and only since the 1900 's has domestic rabbit raising been accomplished in the United States. The first commercial colonies were started in southern California. Meat rationing during World War II gave the infant industry a push.

Today, approximately 200,000 people are engaged in some phase of the rabbit business, and animals are produced in almost every State. Meat processors, serving major cities, market more than 10 million pounds annually. In medical re- search, more than 900,000 animals per year are used for pharmaceutical and vaccine testing. Over the years, the breeds have been improved from the long, rangy, low- meat-yield type to the compact, blocky animal of today. Production has increased from less than 65 pounds of meat per year per doe to a minimum of 120 pounds per doe, and 200 pounds per doe is not un- likely for the future. Feed required to produce 1 pound of meat has been reduced from about 6 pounds to 3.5 or 4 pounds. This publication, based on years of research by Federal and State agencies, will provide a useful reference manual for rabbit growers. It is designed to help ranchers recognize the more common rabbit diseases and to know when professional advice is needed. It is not meant to encourage rabbit growers to diagnose and treat diseased animals without the advice of a veterinarian. There is always the possibility that an animal may be suffering from two or more diseases at one time. Diseases are classified according does at the same time, and then transfer kits from the large litters to the small ones two or three days after kindling to even out the milk supply. to major cause bacterial, viral, nutritional, hereditary, fungal, and miscellaneous, including poisoning, tumors, and vices.

\section{Forage}

Rabbits can be pastured in outdoor pens placed on the ground, which allows them to harvest their own fresh forage. Fryers can be kept in outdoor pens with wooden slats or chicken wire on the floor to prevent the rabbit from digging out of the pen. Pens are moved daily to fresh pasture, and the rabbits are provided with concentrate feed. Ideally, rabbits won't graze the same area of pasture again for at least six months to prevent the spread of coccidiosis.

There are many different production models for raising rabbits on pasture. Some producers chose for rabbits to be born and raised to weaning indoors. The weaned rabbits are then moved to portable cages and pasture. Rabbits raised on pasture may take longer to reach slaughter weight. Rabbits that have been bred for a commercial confinement production may not perform well on pasture. You may have to spend time experimenting with breeds and breeding stock from another pasture producer instead of sock that has been raised indoors and fed only a commercial feed ration.

Growing local feed for rabbits is also an option. Research has been conducted on using water spinach, sweet potato, cassava foliage, mulberry leaves, and other plants and found that such crops can replace or be combined with conventional feed ingredients [2]. Another study claims that growing potato forage along with a small amount of cereal grain for an energy supplement can be selfsustaining program for a small farm [4].

\section{Reproduction}

An important part of reproductive management is taking the female (doe) to the male's (buck's) cage. Otherwise, the buck would spend his time marking new territory in the doe's cage instead of breeding. Breeding should occur within about one minute. If it does not occur, the doe should be removed, and the process should be 
tried again in a few days. The doe should not be left in with the buck for a long period of time because they may fight. Rabbits do not have a heat cycle like many animals do, rabbits ovulate after mating. The doe's abdomen may be palpated 10 to 14 days before breeding to see if she is pregnant. The embryos are round and feel like grapes [5]. Birth of the kits (kindling) occurs in 31 days with NZWs. A nest box with wood shavings or other bedding materials is placed in the doe's age at 29 days so she can pull fur and build a nest. It is a good policy to breed several does on the same day in order to be able to divide large litters at kindling among does. NZWs makes good foster mothers. Being touched by human hands at birth does not harm the kits or cause the mother to reject them. Eight or nine kits with each NZW mother are an appropriate number, cannibalism by the mother is often due to poor nutrition, but sometimes it may have no apparent cause.

Rebreeding can take place about one and a half month after kindling for four to five litters per year. Kits are generally weaned at 30 days of age; however, if the doe is rebred at one and half month after kindling, the kits can be left with their mothers for up to two months. This is a particularly useful practice if cage space is limited. With top nutrition and management, some producers wait only one to seven days after kindling to rebreed the doe for maximum production (up to 11 liters per year). However, does may require a rest after three or four breeding's at this accelerated rate. A good doe sends an average of 50 fryers a year to market. Young rabbits (fryers) should be separated by gender after 12 weeks to prevent fighting and inbreeding.

\section{Management}

It is important to keep production record in order to know when to carry out crucial activities such as putting in the nest box, and to aid in choosing the best replacement stock. Ear tags or tattoos are necessary with large numbers of rabbits. Sanitation is very important. When fur and dust accumulate on cages, they can be removed by burning with a propane torch. Nest boxes should be cleaned and disinfected after use (one ounce of bleach to one gallon of water is a good cleaning solution).

\section{Meat Processing}

Rabbits that receive good nutrition reach a market weight of four to five pounds live weight within 10 to 12 weeks and are marketed as fryers. It may take longer to reach market weight with poorer nutrition. Older rabbits (Usually above six pounds) culled from the herd are less valuable due to tough meat and are marketed as stewers.

Rabbit processing generally consists of stunning or killing the animal, hanging it to bleed, removing the head, removing feet and tails, removing skins, eviscerating, washing the carcass, chilling the carcass in a water tank or refrigerated room, aging the carcass under refrigeration, and packaging. In a plant, an automated line reduces labor for rabbit processing compared to a manual overhead track but is subject to possible electrical breakdowns and other problems. If you are planning to establish a USDA-inspected plant, contact the USDA Food Safety and Inspection Service (FSIS). There is very little information available on building plans for rabbit processing; however, much of the equipment is very similar to or the same as poultry-processing equipment. Also, since rabbits are not classified as livestock, USDA inspection is voluntary [6].

Under voluntary federal inspection, each rabbit and its organs are inspected to ensure it is wholesome, free from disease, and slaughtered under USDA poultry regulations. Voluntary inspection of rabbits (Along with game meats) is handled under the agricultural marking acts [7]. Since rabbit inspection is voluntary the Federal Government does not pay for inspection and the producer must cover the costs. According to the [7], when rabbit is not voluntarily inspected, the processor is subject to food and drug administration (FDA).

\section{Marketing Process of Rabbits}

Marketing rabbit can be difficult and frustrating because there are few processors who buy live rabbit, and supply and demand can be unstable. In the wintertime, producers may have a more difficult time raising rabbit and supply is therefore limited. In the summertime, supply can become glutted. A market report from the American Rabbits Breeders Association is available at www. arbanet/processors.htm. This report includes the name and addresses of processors, along with information on current prices paid for fryers and stewers.

Processing for Market and Home Use 4-H members may dispose of their rabbits in four ways:

Sell live rabbits to a processor for slaughtering; Process them for direct sale; Process them for home use; or Sell them as pets or breeders. Each 4-H member should begin the project with the goal to sell rabbits for meat and fur, rather than to keep them as pets or for breeding. Make arrangements to sell meat rabbits to a processor before fryers are ready for market. Crating and Transporting Live Rabbits

Most rabbits will probably be sent to market live. Properly crated rabbits in good condition can be transported safely, but do not expose them to extreme heat or cold. Good ventilation is important. Avoid overcrowding. Although having individual shipping compartments is better, 4- $\mathrm{H}$ members transporting rabbits for relatively short distances can probably use shipping crates made from packing boxes. As the scope of the project grows, obtain permanent shipping crates.

\section{Marketing Enterprise}

To make your rabbit enterprise financially successful, you must have a way to sell your animals. Your marketing methods and the 
price you receive may determine your ability to pay your expenses and make a profit. By the time a litter is partly grown, you must know how you will market the animals. Select outstanding animals from a strong bloodline (desirable strain) to keep as replacements for older animals or as new additions to the colony. Sell other animals that meet breed or production standards whenever possible to $4-\mathrm{H}$ members or other people wishing to raise rabbits.

You might sell fryers live to commercial rabbit processors or to laboratory animal suppliers. Or, dress and sell the fryers to friends, relatives, neighbors, stores or restaurants. Each of these markets requires a clean, healthy, well-fleshed animal. Be sure to find out the county and state regulations governing the sale of dressed fryers.

Fryers can be sold either as a whole carcass or cut up and ready for meal preparation. It is probably best to use poorer fleshed animals at home. You can sell older animals as roasters or stewers, either live or dressed. Be sure your customers know the kind of animal they are buying and the best way to prepare the meat. The smaller rabbit breeds are often popular on the pet market. Eye appeal, ability to adapt and a good temperament are needed for this type of sale.

Rabbit manure is often in demand. An important part of your enterprise is the worm bed, where fishing worms and garden mulch can be produced. This practice is recommended because it allows you to use the manure in a way that minimizes odor and fly problems. Sometimes you can sell rabbit manure to home gardeners or to people who raise worms commercially.

\section{Direct Marketing}

The United States does not have a history of rabbit consumption. However, there is untapped potential, especially for the natural and organic markets. ATTRA can provide more information on organic production and certification. Direct marketing requires extra time and effort for the producer but provides the opportunity to produce a high-quality product, educate the consumer and develop customer loyalty. In establishing a direct market, you can start with producing meat for family or selling to neighbors and friends. Providing free samples to businesses patronized by the producer, at county fairs, and similar venues can acquaint potential customer with the products. And advertising through newspaper, radio, flyers, brochure, and the internet can be effective. Some farms send out a newsletter to customer describing activities at the farm and emphasizing the quality of their product. Education help to build a loyal customer base.

Presentation to local organizations and civic group may attract consumers interested in lowering fats and cholesterols in their diets. News social media tools can also engage consumers with the farming operation. Customer bases include local health food stores or grocery stores interested in carrying farm-fresh product (This usually requires a steady supply), farmers market, and restaurant.
Beside the sale of meat, rabbit can also be raised and sold for pets and show animals. Thousands of youth across the country participate in 4-H rabbit project shows. Raising rabbits for these purposes is very different than raising them for slaughter. There are dozens of recognized breeds. If you are selling rabbits for show, you must pay special attention to the various characteristics specific to a particular breed. A rabbit field day at a school could provide the opportunity for people to handle live rabbits, sample rabbits meat prepared in different recipe, get pamphlet about rabbit production and qualities of the meat, and see exhibit of craft that can be made from rabbit product, such as rugs from the pelts and rabbit foot key chains. Rabbit producers may be able to coordinate with 4- $\mathrm{H}$ groups or the cooperative extension service in other to carry out a project of this kind [8].

\section{Constraints of Rabbit Production (Health)}

The constraints are the problem encounter by the farmer and the sources of different kind such as health, theft capital, space, feed and others etc. but the major constraints faced is health management and of various diseases such as Mastitis, or inflammation of the mammary glands, is a common disease in rabbits but it is traceable with antibiotics. The bacteria pasteurella causes snuffles and pneumonia; chronic pasteurella sufferers should be culled from the herd. Rabbits showing overgrown teeth, those developing sore hocks, and poor producers should also be culled. If antibiotics are used to treat disease, a withdrawal period is required before slaughter to ensure that residues have cleared the animal's system. Since antibiotics ad hormones are not routinely used in rabbit production, the meat is especially appropriate for natural and organic markets [9].

\section{Vaccine development, approval and monitoring}

Vaccine research and development requires years of investment and expertise from veterinary scientists to produce suitable vaccines that meet high standards of safety, quality and efficacy as assessed and approved by independent regulators, which are the Veterinary Medicines Directorate (VMD) in UK and the European Medicines Agency (EMA) in the EU. Even after a vaccine is approved and becomes available for pets, animal medicine companies continue to support the safety and efficacy of their vaccines through a process of pharmacovigilance. Pharmacovigilance means vets and owners can report any suspected adverse reactions, which must then be reviewed by animal medicine companies and the VMD. Serious adverse reactions are very rare. Nevertheless, ongoing assessment helps to reduce these rare events even further. These responsibilities are taken seriously by animal medicines companies who continue to work and ensure that vaccines remain safe and effective into the future [10].

Rabbit Vaccines and Vaccination Vaccines are available for the two main diseases of pet rabbits in the UK, namely myxomatosis and rabbit haemorrhagic disease (RHD) type 1 and type 2 . It is 
widely recommended that pet rabbits are vaccinated against these serious viral diseases as part of a preventative healthcare plan [11] As the characteristics of individual vaccines can differ, the timings for vaccination and the frequency of booster vaccinations will depend on factors such as the duration of immunity from specific vaccines. Your vet will advise on appropriate timings based on the specific product information that can be found on associated product literature (the Summary of Product Characteristics or SPC or the datasheet).

The benefits of vaccination can be exerted beyond the protection of individual rabbits. The prevalence of disease in regional communities can also be reduced by decreasing the overall numbers of susceptible rabbits that have not been vaccinated [12]. When a high proportion of rabbits in the community are vaccinated the protection offered is called 'herd immunity'.

A vaccination appointment not only helps to protect your animal against infectious diseases, it also enables pet owners to discuss any concerns with their veterinary surgeon and allows the vet to perform a full health examination and diagnose any issues that need to be addressed, nipping potential problems in the bud We have a legal and moral responsibility to protect the animals in our care from pain [13], suffering and disease. Responsible rabbit ownership includes regular veterinary health visits and ensuring preventative steps are taken to avoid the negative welfare consequences of ill health. Working with vets, owners can proactively take steps to ensure reasonable preventative measures are taken to protect the health and welfare of their pet rabbits.

\section{Factors in Prevention and Control}

The only rabbit that will return a profit to its owner is a healthy one. Factors conducive to good health include: Body soundness and livability, Adequate nutrition, Suitable environment, Prevention, eradication, and control of transmissible diseases [14].

\section{Body Soundness and Livability}

Sound, vigorous rabbits are necessary both as quality meat products and as replacementstock. The background of animals saved for breeding should be examined care- fully so that recognizable defects will not be perpetuated. A healthy, mature breeder, that has a history of several litters showing fast development, good reproduction, and high livability of the young, and relative freedom from disease, is a better source of replacement stock than a rabbit that has not shown these traits. Healthy, well-framed, well-fleshed mature does producing litters containing from 8 to 12 live young, with low mortality in fryers, good feed conversion, and high weights, should be marked as potential sources of breeding stock.

Each individual selected for breeding should be carefully examined for defects and for general health. Deviations from normal should lead to elimination [15]. Through rigid exercise of this practice, a profit- able, high-producing herd can be established.

\section{Adequate Nutrition}

The simplest diet sustaining good health, growth, and reproduction is preferred. Decline in normal health may increase susceptibility to disease agents and cause heavy monetary loss. Slow growth and development may be as costly as disease mortality. Finally, the rabbit must be more than just healthy; it must reproduce and raise young profitably.

\section{Suitable Environment}

The term "environment" includes every factor that influences the life of the rabbit. Some of these factors are hutch size and location, nearness to other animals, dryness, temperature, amount of sunshine, shelter design, availability of water, and general management. Careful examination and control of the environment are essential for effective disease prevention.

\section{Prevention, Eradication, and Control of Transmissible Diseases}

If disease prevention has failed and transmissible diseases are established in the rabbitry, heavy mortality may lead to business failure. Pasteurellosis, ear mange, and coccidiosis are diseases commonly experienced by some growers. These infectious diseases are usually introduced in two ways, by contact or by mechanical carriers. The adult rabbit is the most important contact carrier. An animal may apparently recover from a disease, but still shed infectious organisms in the feces, urine, or in droplets exhaled while breathing. Pasteurellosis and liver coccidiosis are important diseases spread by contact. The grower who introduces new stock directly to his herd or who exhibits animals at shows and fairs is most susceptible to disease outbreaks. New or exhibition animals should be held in a special isolation section of the colony until the rancher is reasonably certain that they are disease free. Rabbits that are carriers of disease are often not recognized because they appear healthy. Tests to pinpoint which animals are carriers are not always practicable. Liver coccidiosis is found when the fryer is dressed out for market, too late for trace back to the doe that produced it. Bacterial cultures of the nasal cavity may show the presence of pasteurellosis, but the cost of these tests usually prohibits

The grower from utilizing them. When disease prevention has failed, we must consider the means available to control and eliminate the disease. When liver coccidiosis is involved, the adult carrier may be freed from infection by chemo- therapy, plus the establishment of improved management practices. In some cases, it may be necessary to depopulate to eliminate a disease. The time between depopulation and repopulation with clean, healthy animals depends on many factors. Environment plays an important part in the time interval involved. Mechanical transmission of disease occurs when the infectious agent is accidentally carried from place 
to place. Man is the chief offender. The grower who treats a sick animal and then moves on to check or count newborn young can be an important carrier of respiratory infection and coccidiosis. Feed salesmen, servicemen, and pickup buyers and visitors who have made the rounds of other rabbitries may be sources of infection. The grower himself should avoid visiting other rabbitries if disease is known to be present. These examples may be considered extreme, yet they hap- pen repeatedly and are definite factors in introduction of disease. Dogs, cats, birds, and rodents have been incriminated in carrying diseases to rabbits and should be kept out of the rabbitry. Insects also should be controlled [16].

\section{Sanitation Program}

A constant sanitation program is an important part of disease prevention. A program of cleanliness is required to establish and maintain a safe environment in which animals can live and reproduce. Elimination of disease carriers is most important. Environmental factors must be considered in any sanitation program. Particularly important is the proper type of hutch and shelter construction and its maintenance. The ease of cleaning, the supply of clean water, and the space for Iodent-proof feed storage are important items when building a production unit. Proper drainage is another factor. Provision should be made for water run- off from the rabbitry area. Hutches should be constructed so that individual units may be removed for disinfecting. The number of animals per unit should be adjusted to the area and the environment. Overcrowding requires more effort to keep the area clean, dry, and well ventilated. Unfavorable environmental factors lower the animal's resistance to disease and facilitate the spread of infection. Water should be fresh, clean, and protected from contamination by urine, fecal matter, and feeds. Cleaning water containers frequently is important.

Feed may act as a mechanical carrier for infection when contaminated with feces. Protecting the feed from contamination by the use of properly designed and well-constructed feed hoppers is necessary in any good sanitary program. All feeders should be cleaned periodically. Good feed utilization and waste removal are important in disease prevention. Feed scattered about the rabbitry attracts insects, mice, rats, and birds all potential carriers of disease. Proper storage of bulk feed will aid the sanitation program. In the small rabbitry or where large quantities of bulk feed are not stored, metal garbage cans with tight lids are good feed storage containers.

\section{Disinfection}

Disinfection refers to the killing of infectious agents such as bacteria, viruses, and parasites. To facilitate the use of disinfectants, all equipment and other construction should be as simple and easy to clean as possible. Fecal matter and other organic material protect disease-producing bacteria, viruses, and parasites and nullify the effectiveness of even the most efficient disinfectants. Thorough scraping and washing should precede disinfection. One com- pound should act as both cleanser and disinfectant. In the routine cleaning and disinfecting of pens and sheds in a small rabbitry, ordinarily solution is effective and economical.

One 13-ounce can of lye is enough to make 15 gallons of cleaning and disinfecting solution. For large ranches, it is advisable to buy the lye in the form of caustic soda. Each pound makes about 20 gallons of solution, which does not need to be heated although heating is advisable. In addition to acting as a disinfectant, lye cuts grease and partly dissolves and penetrates fecal material. Use of lye has some disadvantage. Concentrated lye is a poison and is destructive to aluminum paints and clothing. The lye may be slightly irritating to the hands and face of the operator. Consequently, take precautions to avoid excessive exposure of the skin during the disinfecting process. Keep containers of lye tightly covered. Some ranchers use steam under pressure to clean and disinfect pens and equipment. When steam is used, caked fecal material should first be soaked with water. Use of a good cleansing compound, followed by steam, cleans and disinfects very satisfactorily. Sunlight is a potent disinfectant if the equipment is very clean and sufficient exposure time is allowed. A cement slab exposed to the direct rays of the sun is a good place to disinfect movable equipment. Dry heat in the form of a flame is effective as long as the flame is in direct contact with the infectious agent. Care must be taken as this procedure is a fire hazard [17].

\section{Practices to Maintain Health and Prevent Disease}

The successful grower observes good sanitation and management, feeds an adequate diet of simple ingredients, and gives the animals plenty of fresh water. Daily inspection of all animals in the herd is important. When sick rabbits are first noticed, the grower should immediately try to deter- mine the cause. The following course of action is suggested: 1 . Mark or note pens that contain sick animals. 2. Isolate sick animals. It is best if they can be kept in rooms or buildings separate from healthy rabbits. 3 . Care for the sick animal only after all other rabbits in the herd have been cared for to prevent carrying infection from sick to healthy rabbits. Be sure to wash hands and disinfect boots after caring for sick animals. Clean and disinfect any equipment moved from the area of sick animals to the clean animals. 4 . If the cause of the trouble can- not be quickly determined, a few typically sick rabbits should be sent to a diagnostic laboratory. 5. Destroy all hopelessly sick animals and bury or burn all dead animals. Open pits are not recommended. 6. Clean and disinfect all pens before placing new rabbits in them. Use a 2-percent lye solution (1 pound of lye to $51 /^{\wedge}$ gallons of water). The solution is effective against most viruses and bacteria.

\section{Bacterial Diseases}

\section{Pasteurellasis}

Pasteurellosis is the designation for all diseases associated with Pasteurella multocida. The disease manifestations are varied 
and include snuffles, pneumonia, pyometra, orchitis, otitis media, conjunctivitis, subcutaneous abscesses, and septicemia.

Snuffles The mucous membranes of the nasal sinuses become infected by bacteria in the inspired air or by direct contact with infected animals or contaminated objects. The clinical disease is characterized by a catarrhal (mucus or pus) nasal discharge (). The extent to which the infection spreads into the lower respiratory passages depends on the virulence (invasiveness) of the bacteria and the susceptibility of the animal. If the disease is con- fined to the upper passages, the first signs are sneezing followed by a nasal discharge. The inner aspects of the rabbit's forepaws may be caked with exúdate because of at- tempts to wipe the exúdate away from the nose. Pasteurella bacteria sometimes are found in the nasal sinuses of healthy-appearing rabbits. Stress resulting from extremes of temperature, high humidity, pregnancy, and lactation is a primary factor in the development of snuffles.

\section{Pneumonia}

Upper respiratory disease (snuffles) may spread to the lungs and cause pneumonia. rabbit mortality surveys reveal pneumonia to be present in 25 percent of the animals examined; it is the greatest single cause of death in mature animals. Signs of pneumonia are depression, labored breathing, bluish eye color in albinos, and a nasal discharge. The body temperature is usually above normal. Gross lesions of the lungs appear as red consolidated areas, sunken purple areas, and abscesses. The consolidated lesions are most often in the anterior lobes of the lungs. A catarrhal exúdate is found in the air passages. Abscesses appear with thin fibrous capsules close to the surface of the lungs. Sometimes there are adhesions between the wall of the chest cavity and the lungs. Good ventilation without drafts, low humidity, and treatment with antibiotics are recommended. Pasteurella organisms are sensitive to oxytetracyclines, streptomycin, sulfaquinoxaline, and furazolidone.

\section{Pyometra}

Means pus in the uterus. The walls of the uterus usually are dilated, and the organ is filled with pus. Affected females will not reproduce and, therefore, are culled and often slaughtered. Pyometra results from the introduction of Pasteurella bacteria into the uterus during mating and may be traced to a single buck with a chronic infection of the testicles. Treatment of pyometra is seldom attempted because the disease is usually not noticed until the female is slaughtered. Successful treatment is unlikely.

\section{Viral Diseases}

\section{Myxomatosis}

Myxoma virus was first isolated in South America from diseased laboratory rabbits; the virus was later found to be a widespread natural infection in cottontails. In wild cottontails, it causes only mild tumors, which regress after several weeks; the disease is fatal only in the very young. In contrast, the disease can completely wipe out some susceptible populations of domestic rabbits. Confirmed cases of myxomatosis follow the geographical distribution of the California brush rabbit, which is limited by the Pacific Ocean, the Columbia Eiver in Oregon, the Cascade- Sierra Nevada Mountains, and the tip of the peninsula of lower California. Transmission of the disease by mosquitoes led to the name "mosquito disease." Myxomatosis is also referred to as "big head disease" because of edema around the eyes, ears, lips, and nose in the early stages of the infection. Clinical signs include lusterless eyes with a purulent discharge and elevated body temperature. Edema of the ears causes them to become heavy and pendulous (fig. 8). As the disease progresses, edema of the genital region and a nasal discharge occur; death follows in 10 to 12 days. In the few cases that Myxomatosis Myxoma virus was first isolated in South America from diseased laboratory rabbits; the virus was later found to be a widespread natural infection in cottontails. In wild cottontails, it causes only mild tumors, which regress after several weeks; the disease is fatal only in the very young. In contrast, the disease can completely wipe out some susceptible populations of domestic rabbits. Confirmed cases of myxomatosis follow the geographical distribution of the California brush rabbit, which is limited by the Pacific Ocean, the Columbia river in Oregon, the Cascade- Sierra Nevada Mountains, and the tip of the peninsula of lower California. Transmission of the disease by mosquitoes led to the name "mosquito disease." Myxomatosis is also referred to as "big head disease" because of edema around the eyes, ears, lips, and nose in the early stages of the infection. Clinical signs include lusterless eyes with a purulent discharge and elevated body temperature. Edema of the ears causes them to become heavy and pendulous (fig. 8). As the disease progresses, edema of the genital region and a nasal discharge occur; death follows in 10 to 12 days. In the few cases that survive, widespread subcutaneous gelatinous tumors develop all over the body. Rabbits dying from myxomatosis exhibit no characteristic internal changes by which the infection can be definitely diagnosed. Usually, there is congestion and consolidation of the lungs, and the spleen is enlarged, dark red, and pulpy. The cut surface of each edematous sub- cutaneous tissue is white, gelatinous, and glistening; when pressed, clear fluid exudes. Clinical signs and tissue examination are required for diagnosis, which is confirmed by inoculation of test rabbits and virus isolation. The virus is spread by direct con- tact and by biting insects, such as mosquitoes and fleas, which act as mechanical vectors. Control consists of prompt identification of the disease and destruction of infected animals. Practices that reduce mosquito populations, such as draining or spraying breeding areas, should be followed. Screening the entire rabbitry is an effective but costly solution. Antibiotics are not effective in treating sick animals, but an attenuated vaccine has been developed, which covers protection [18].

\section{Rabbit Pox}

The disease can occur with or without clinical disease being manifested. In either case, the lesions include lymphadenitis, 
popular nodules on the mucous membranes, and orchitis. Mortality is highest among the unweaned young and may approach 75 percent. Rabbit pox virus is rarely a cause of epizootics, but it is usually very serious when it does occur. Vaccination with vaccinia virus confers immunity.

\section{Fibrama}

Rabbit fibroma virus was isolated from nodules beneath the skin of wild cottontail rabbits. These fibromas (growths) were trans- mitted to both wild and domestic rabbits. It was once believed that fibroma virus only infected wild rabbits; however, an outbreak was recently reported in a commercial rabbitry. In the cottontail rabbit, fibroma virus causes a benign tumor which regresses within a few weeks. Young domestic rabbits, on the other hand, develop small subcutaneous nodules to diffuse indurations involving muscle and tendon. The external genitalia become red and swollen. Death is frequent in unweaned young. The cut surfaces of the nodules are pale and glistening and may have radiating white streaks. In young animals, the tumors are more widely spread over the body and often coalesce. There may be involvement of the kidneys, liver, intestinal tract, bone marrow, and mesentery. The role of mosquitoes and other insects as vectors of rabbit fibroma virus has been established. Given the proper environment (such as an epizootic in wild cottontail rabbits) and an adequate mosquito population, this viral disease could result in significant economic loss of young domestic rabbits.

\section{References}

1. Oseni SO, Ajayi B. Komolafe SO, Siyanbola O, Ishola M, et al. (2008) small holder Rabbit production in south weatern Nigeria: Current Status, emergency Issues and way forward 9th world Rabbit congress, Verona, Italy, pp. 1597-1602.

2. Samkol P, SD Lukefatir (2008) A Challenging Role for organic Rabbit production Towards Poverty Alleviation in Soulth East Asia 9th world Rabbit Congree, Verona, Italy.

3. Ray Molbay (2008) Behaviour and performance of growing Rabbits under various floor types. Global Vegetarian 14(1): 149-153.

4. Lukefahr Steven, G Schuster, KG Mc Caution, T Verma, R Flores (2010) Self Sustaining Rabbit Projects A pilot Study involving feed of sweet potatoes porage proceedings of the $4^{\text {th }}$ Rabbit Congress of the Americans Carsoba, Argentina.

5. Gill Charlie (2004) The art of Palpation Country Size Magazine.

6. USDA-APHIS-VS (2002) US Rabbits industry profile United States Department of Agricultural Animal and Plant Health Inspection Service/ Veterinary Services Centres for Epidemiology and Animal Health, centre for emergency Issues, Fat Collins, USA.

7. USDA Fsis, (2006) Rabbit From farm to Table Fact Sheet.

8. 4-H Ontario (2008) US Department of Agriculture marketing Services. United State Classes, Standard and Grades for Rabbits, USA.

9. Attamah JM, Atlamah CO, Mnodim ME (2008) Disease Management practice among Rabbits farmers in Enugu State Nigeria. Journal of Agricultural extension 22(3).

10. Baruwa IO (2014) Profitability and constraints to rabbits' productions under tropical conditions in Nigeria. journal of livestock sciences 5: 8388.

11. Tom W Smith (2007) Emeritus, Professor of poultry Science, Mississippi State University. Extension Service of Mississippi State University, cooperating with US Department of Agriculture Published in furtherance of Acts of congress.

12. FAO (2008) The Rabbit Husbandary, health and Production Chapter 6: Housing Equipment, produced by agriculture consumer protection. FAO corporate Document Repository.

13. Grund AS (2016) Animal Kingdom: Effects of Animal Diseases or bis Biosciences. USA.

14. Lamidi WA (2005) Environmental and Different Management Systems in Rabbit Does. A review American Journal of Environmental Policy and manamegment 1(3): 51-56.

15. LukeFahr Steven, PR Cheeke, JI MCNITT, NM Patton (2004) Limitation of intensive meat rabbit production in North America. A Review Canadian Journal of Animal Science 84: 349-360.

16. Mailafia S, Onakpa MM, Owoleke OE (2010) problems and prospects of Rabbit Production in Nigeria- A review. Bayero Journal of Pure and Applied Science 3(2): 20-25.

17. Mbutu EMM (2018) Factor influencing Rabbit farming.A Case of Rabbit Production project in Abothguchi west division, Meru Country Kenya Department of Agricultural Economics. University of Marrobi, Kenya.

18. Owen JE (1976) Rabbit production in tropical development centres. A review Trop Sci 18(4): 203-210. 